\title{
Medicines Regulation in Africa: Current State and Opportunities
}

\author{
Margareth Ndomondo-Sigonda ${ }^{1,2} \cdot$ Jacqueline Miot $^{1} \cdot$ Shan Naidoo $^{3} \cdot$ \\ Alexander $\operatorname{Dodoo}^{4} \cdot$ Eliangiringa Kaale ${ }^{5}$
}

Published online: 3 November 2017

(c) The Author(s) 2017. This article is an open access publication

\begin{abstract}
Sound regulatory systems are critical for protecting public health against use of medical products which do not meet international standards of quality, safety and efficacy. This review provides a summary of the current status of National Medicines Regulatory Authorities (NMRAs) in Africa, and various initiatives that have been established to improve their performance. All countries in Africa (except Sahrawi Republic), have NMRAs but their organizational set-up and functionality is variable. Some are located within Ministries of Health and others are semiautonomous. There is progressive improvement in regulatory capacity, particularly in quality control and postmarketing surveillance, pharmacovigilance and clinical trials oversight. The African Vaccines Regulatory Forum, African Medicines Regulatory Harmonization Initiative, Network of Official Medicines Control Laboratories and WHO Prequalification Scheme have helped countries strengthen their regulatory capacities. The potential establishment of the African Medicines Agency (AMA) in 2018 is an opportunity to improve NMRAs' capacity in Africa.
\end{abstract}

Alexander Dodoo

alex.dodoo@who-pvafrica.org

1 Pharmacology Division, Department of Pharmacy and Pharmacology, Faculty of Health Sciences, University of Witwatersrand, Johannesburg, South Africa

2 New Partnership for Africa's Development, Midrand, South Africa

3 Graduate School of Public and Development Management, University of Witwatersrand, Johannesburg, South Africa

4 WHO Collaborating Centre for Advocacy and Training in Pharmacovigilance, University of Ghana, Accra, Ghana

5 Muhimbili University of Health and Allied Sciences, Dar es Salaam, Tanzania

\section{Key Points}

All African countries, except one, have National Medicines Regulatory Authorities

No national medicine regulatory authority in Africa can undertake the full range of regulatory functions

The proposed African Medicines Agency provides an opportunity for harmonizing and strengthening NMRAs in Africa

\section{Introduction}

Medical products, including medicines (drugs), vaccines, blood products, diagnostics and medical devices are critically important for healthcare delivery in all countries. Every country needs an assured supply of safe, efficacious, good quality and affordable medical products to promote public health and patient care [1]. Sound and effective regulatory systems are needed to ensure the quality, safety and efficacy of medical products and for promotion of trade and socioeconomic advancement [2]. Medical products are highly regulated due to the critical role they play in society and the complexities, and sometimes controversies, associated with assessing their safety, quality, efficacy and effectiveness [3]. All countries therefore need to have effective and efficient National Medicines Regulatory Agencies (NMRAs).

Globally, the World Health Organization (WHO) estimates that at least $30 \%$ of NMRAs have limited capacity to perform the core regulatory functions [1]. According to WHO, there are 54 NMRAs in Africa, but 
their capacity is variable with most of them incapable of performing the core functions expected of NMRAs [1]. The WHO report shows that only $7 \%$ of African countries have moderately developed capacity with more than $90 \%$ having minimal or no capacity [4]. The absence of functional NMRAs in any country (i) exposes the population to potentially unsafe medical products of variable quality and effectiveness; (ii) facilitates the proliferation of substandard, spurious, falsely labelled, falsified and counterfeit (SSFFC) medical products; and (iii) prevents rational use of medical products, all of which are detrimental to public health and patient safety $[5,6]$.

Historically, NMRAs were first established in Britain (1880s), Switzerland (1900), USA (1906), Norway (1928) and Sweden (1934) mainly for patent protection and trade promotion, though the laws in Norway and Sweden focused on product safety as well [7]. In the USA, the death of 100 people after intake of sulphanilamide elixir prompted legislation (Pure Food and Drugs Act, 1938) to be passed that required assessment of safety before any product is sold. In the early 1960s, the thousands of pregnancies affected by thalidomide-induced phocomelia and other defects served to transform drug safety and drive the establishment of NMRAs globally [8].

This led to action from the WHO and its member states that called for rigorous testing of medicines during development and after their release for general use [9]. Currently, no medical products are permitted to be sold in any country unless these products have been approved by the respective NMRAs. The absence of well-resourced and functional NMRAs, therefore, has the effect of restricting access to life-saving commodities [10].

Understanding the current state of NMRAs in Africa provides a basis for identifying gaps and existing opportunities for improving regulatory capacity, promoting public health and advancement of pharmaceutical industry. This manuscript draws upon original research, published reports and data from the New Partnership for African Development (NEPAD) Agency and the WHO, including the WHO Pharmaceutical Sector Profiles and Country Reports [11], as well as policy statements and documentation, to provide an overarching summary of NMRAs in Africa. It also discusses opportunities for strengthening NMRAs' performance, including the role of the African Vaccines Regulatory Forum (AVAREF), Network of Official Medicines Control Laboratories (NOMCOL), African Medicines Regulatory Harmonization (AMRH) Initiative, and others that are aimed to improve the regulation of medical products in Africa.

\section{Current State of Medicines Regulatory Systems in Africa}

Effective regulation of medical products requires a comprehensive legal basis with appropriate and adequate governance mechanisms; sound technical expertise and scientific tools; sustainable funding; coordination of regulatory activities; and monitoring and evaluation to assess performance $[6,12]$. The legal basis gives the NMRA power to perform a function while the level of autonomy in executing its mandate, the appropriate structure that allows for proper coordination of various regulatory activities, availability of financial resources and adequate number of human resources with requisite competency to carry out their duties are prerequisites to its performance [13]. The core NMRA functions include: marketing authorization (MA); licensing of manufacturing establishments; imports and export control; inspection of manufacturing premises and distribution channels; market surveillance (product quality monitoring, pharmacovigilance, control of drug promotion and advertising); quality control; and oversight of clinical trials on drugs [12].

This paper focuses on policy and legal basis for regulation; organisational set-up; management systems; financing mechanisms; human resources and performance of core NMRA functions.

\subsection{NMRAs Organizational Setup, Financing and Management System}

According to WHO, there are 54 NMRAs in Africa [1]. All countries in Africa except the Sahrawi Republic have an NMRA or an administrative unit carrying out some or all tasks expected of NMRAs as shown in Table 1. One country-United Republic of Tanzania-has two NMRAs, namely the Tanzania Food and Drugs Authority and the Zanzibar Food and Drugs Board. While NMRAs in Africa have varying degrees of maturity, their organisational structures, remits and activities also vary widely, some being semi-autonomous whilst others operate within the Ministry of Health $(\mathrm{MoH})$. Some regulate only medical products, whilst others regulate food and cosmetics as well. All NMRAs eventually report to the MoH with the Minister of Health having overall responsibility.

The limited available data on NMRAs' financing show the main sources of revenue for NMRAs are fees for registration, annual product maintenance, plant audit, premises licensing, import permits, and government subvention and donor funding. A study on the East African Community (EAC) NMRAs shows that the Tanzania Food and Drugs Authority (TFDA), Kenya Pharmacy and Poisons Board (KPPB) and National Drug Authority (NDA) of Uganda 


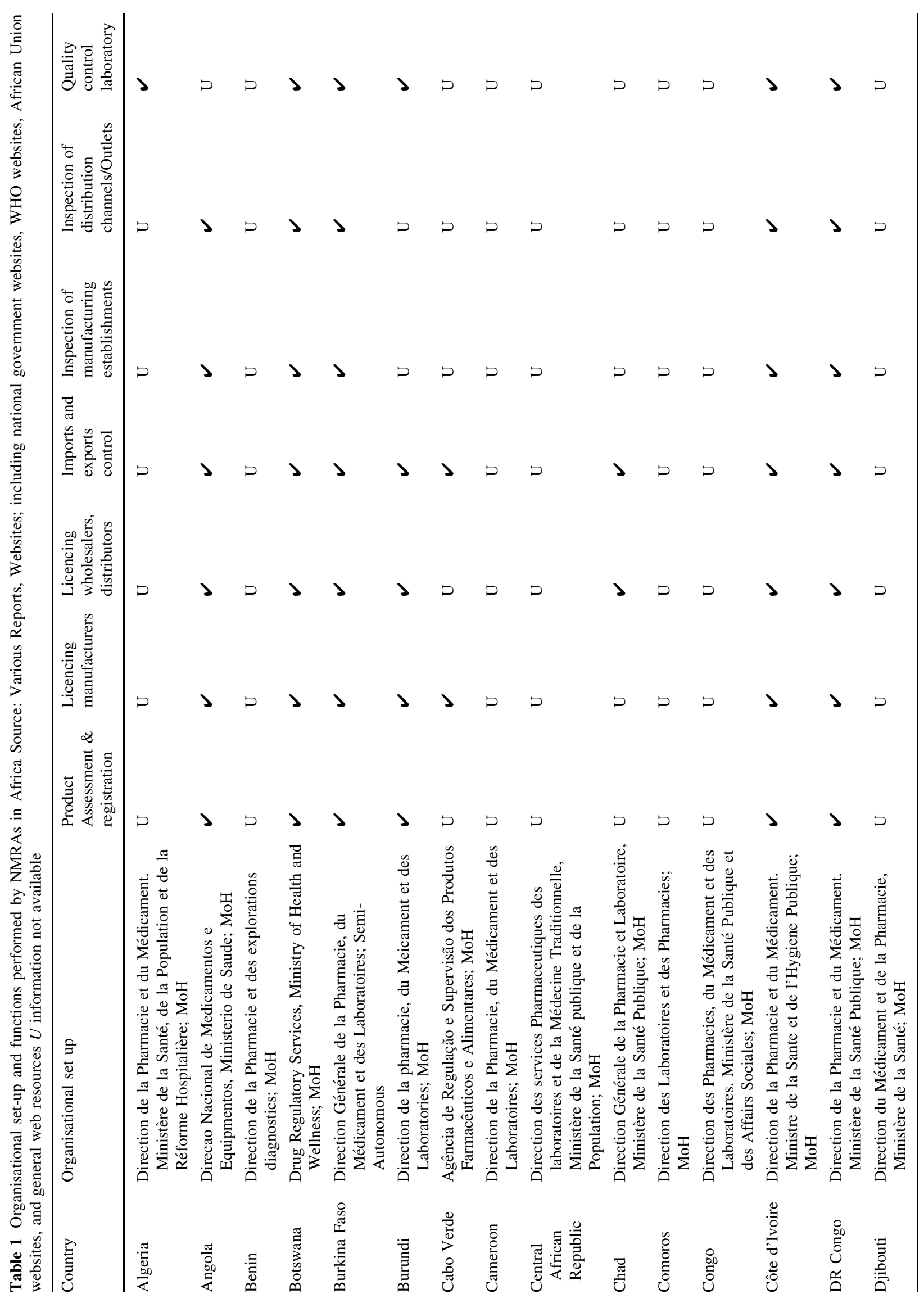




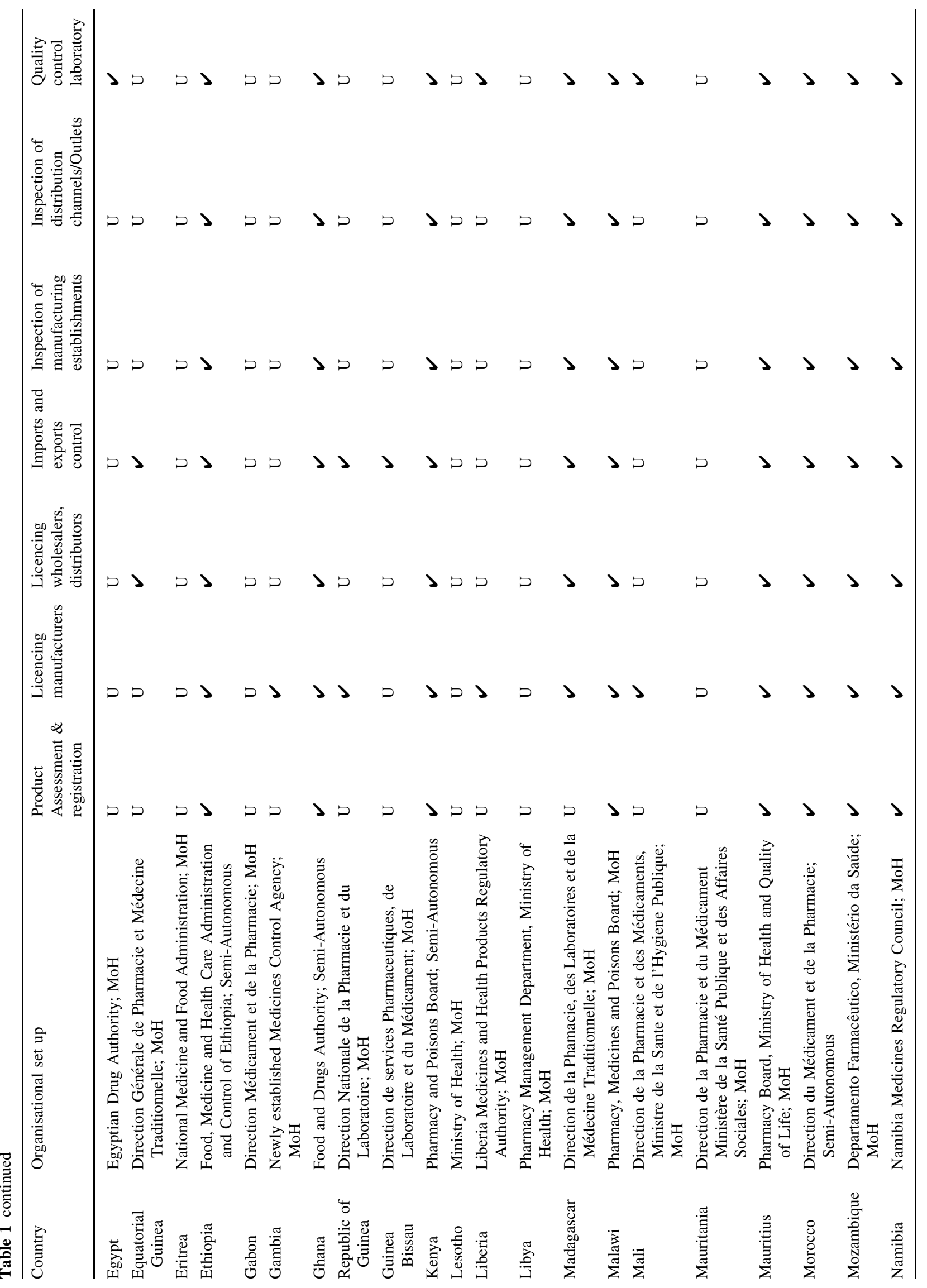




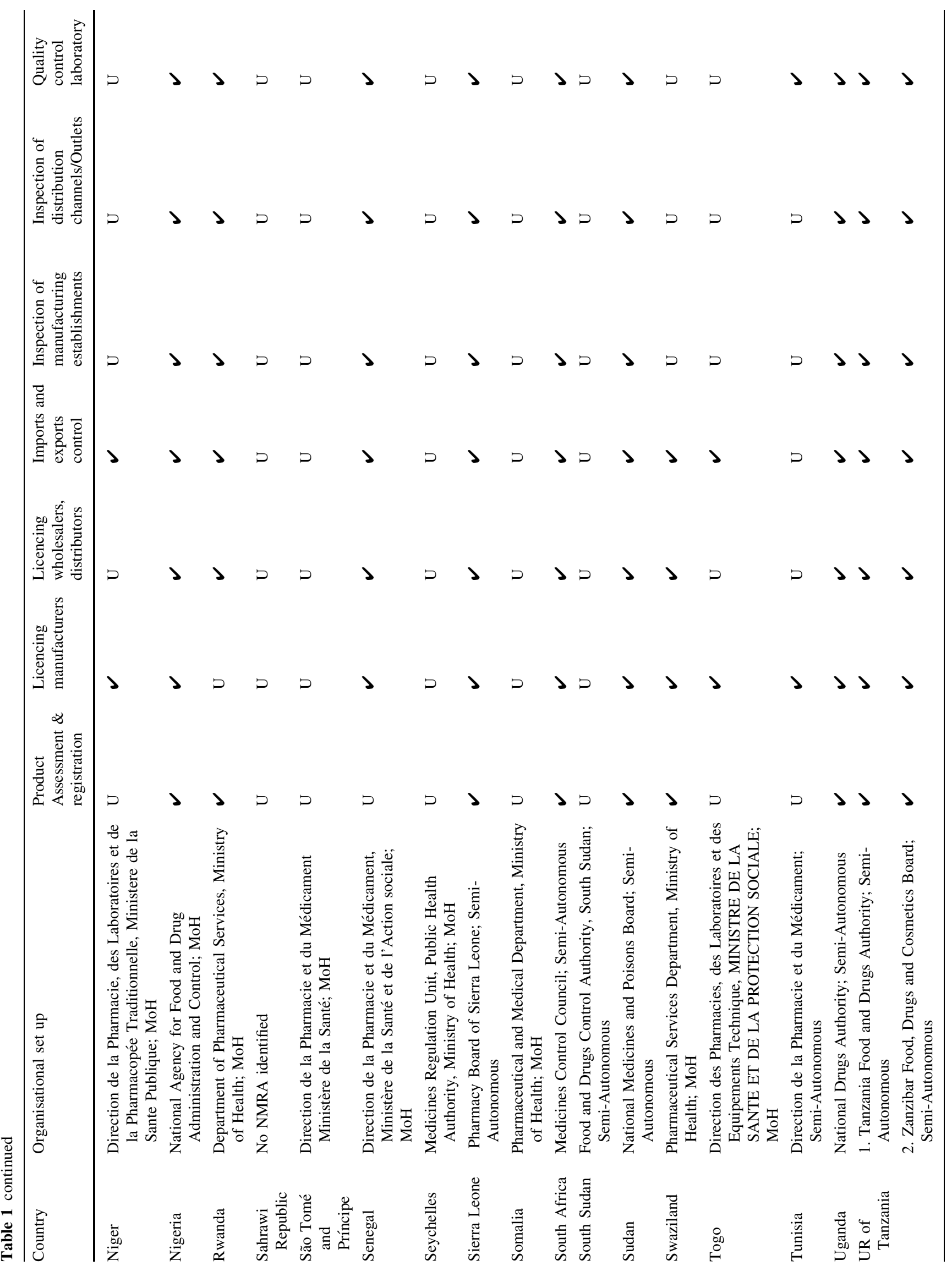




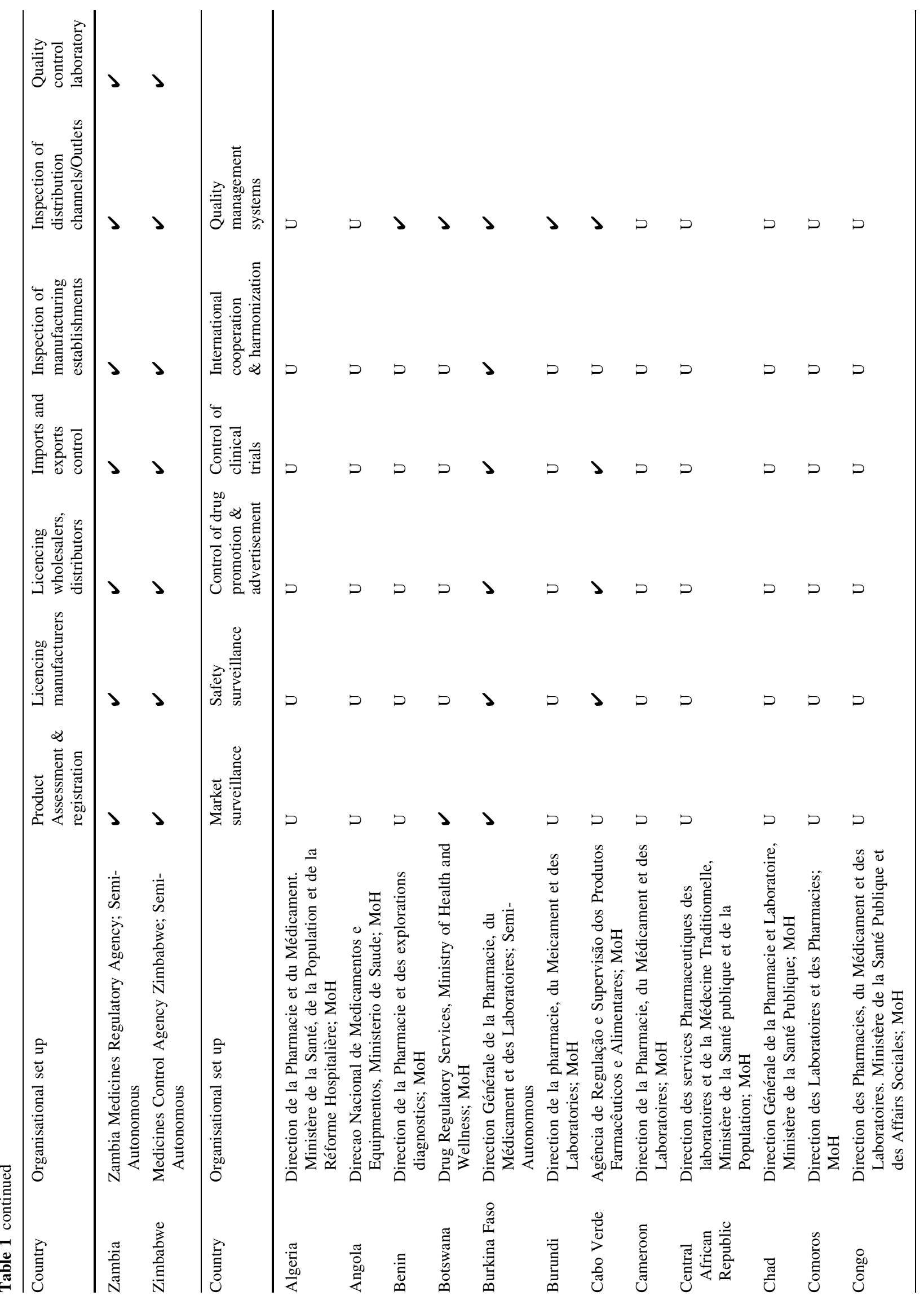




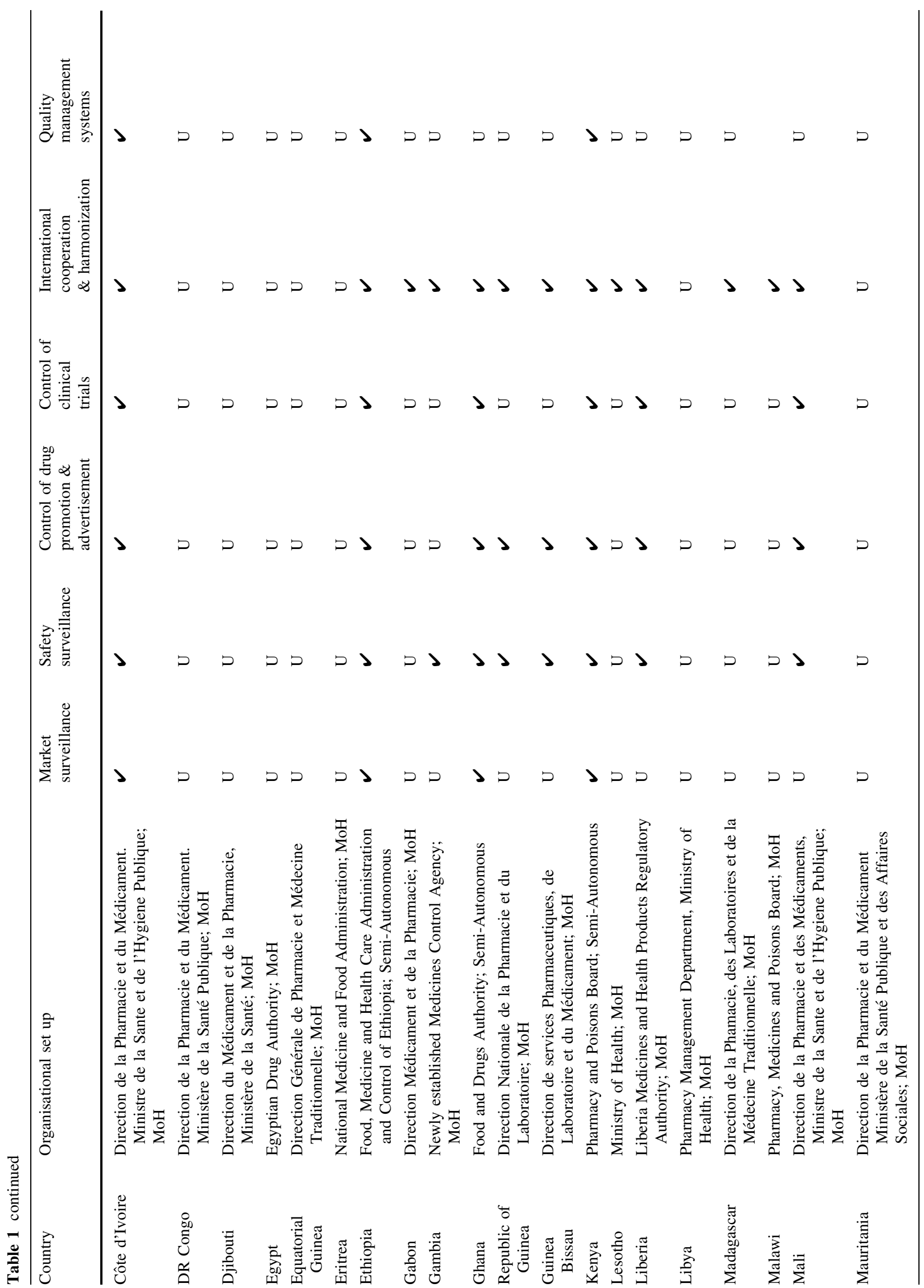




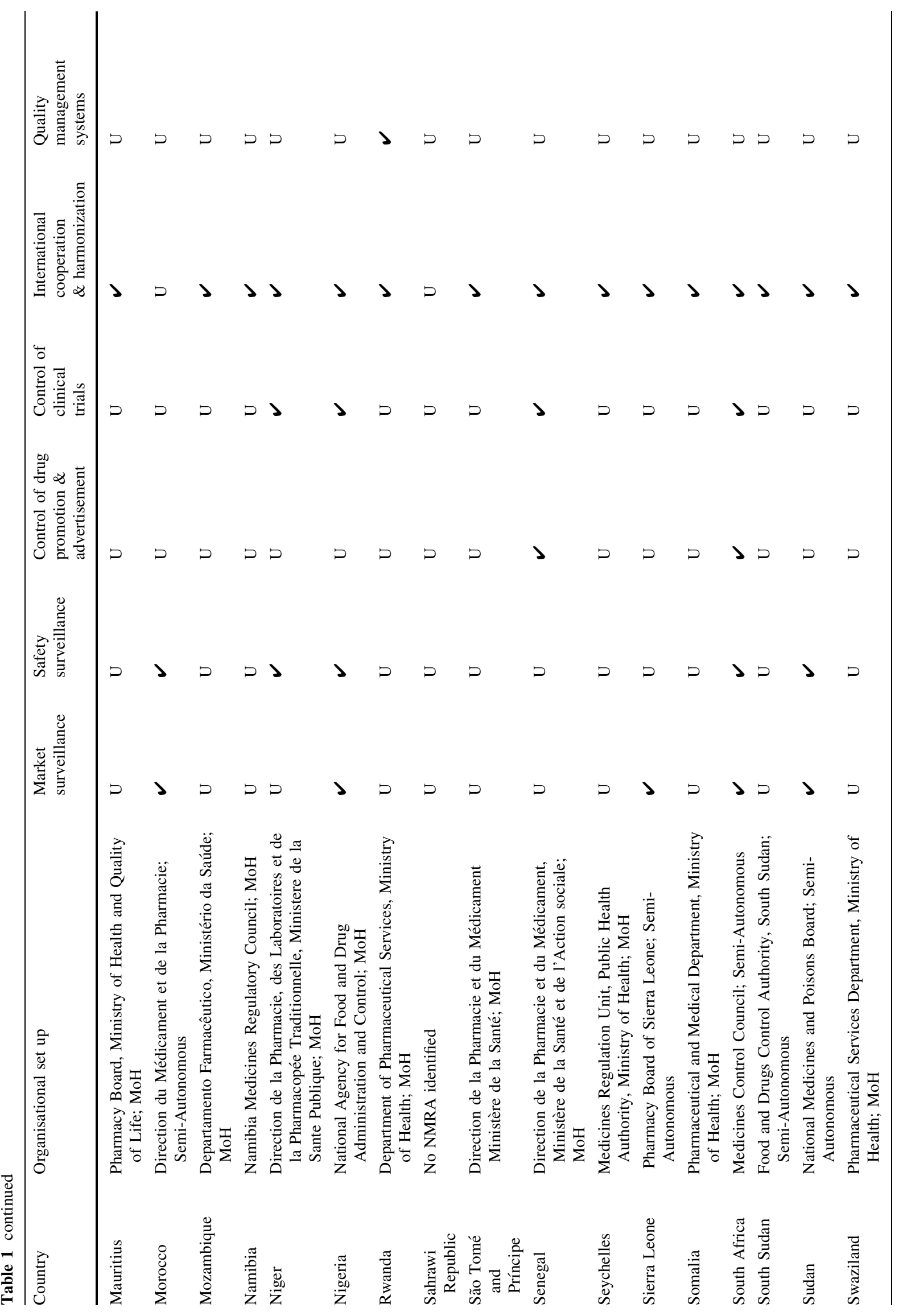




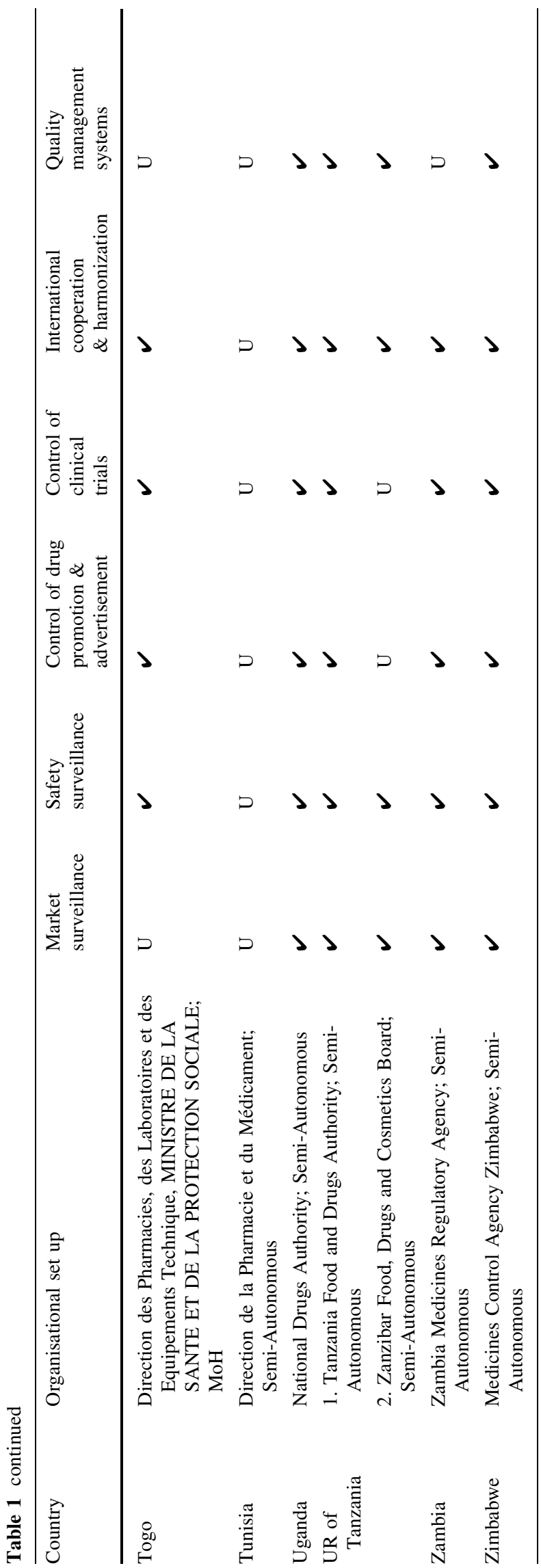

charge fees for regulatory work and receive minimal or no government subvention, while in Zanzibar, Rwanda and Burundi, governments fully fund regulatory work [14]. Similarly, in the Southern African Development Community (SADC) region, the Governments of Lesotho and Namibia fund their NMRAs fully, while in Malawi, Tanzania, Zambia and Zimbabwe, most of the funds are from industry fees. Of 26 countries included in a study, 35\% of the NMRAs depended on government funding, with all fees paid directly to Treasury, whereas $15 \%$ of NMRAs received donor funding, with most countries charging fees for initial MA of products, renewal and retention. Fees for importation of products were rarely charged [12]. More research is needed to determine the various funding models for NMRAs in Africa and mechanisms that will ensure sustainability.

Looking at human resources for NMRAs, reports indicate a general lack of qualified assessors and inspectors [12]. A study conducted in Angola revealed critical understaffing in the Department of Pharmaceutical Inspection (DIF), with a total of 33 staff members at central level, 2 inspectors per province and 1 inspector per municipality [15]. In the EAC countries, there is a general human resource constraint of staff to assess applications and issue licences [16]. Inadequate and unsustainable availability of human resource is a problem affecting most developing countries and is largely caused by low salaries, scarcity of pharmaceutical and other essential professionals, shortage of training institutions, inflexible recruitment procedures, lack of career structure and incentives, and the 'brain drain' [17].

While it is generally agreed that most NMRAs in Africa lack qualified experts to perform critical regulatory functions, the existing literature focuses largely on availability of human resource development plans, job descriptions and responsibilities of key personnel [12]. Literature is sparse when it comes to recording actual numbers of those employed and the requisite expertise and competencies matched to various regulatory functions. Quantifying the existing regulatory expertise in Africa is important, especially given the enormous investment by governments and development partners in training of regulatory experts.

\subsection{Policy and Medical Products Regulatory Framework}

National Medicines Policies (NMPs) are overarching government commitments to ensure access, quality, and rational use of drugs in a country including a statement on regulation of medicines [18]. Most African countries have NMPs which support regulation of medical products. For instance, review of NMP frameworks in the SADC region shows that, with the exception of Seychelles, most of the 
medicine laws in the region are backed by NMPs [19]. In the Central African region, Angola, Chad, Equatorial Guinea and the Democratic Republic of Congo have NMPs in place, whilst in the Economic Community of West African States (ECOWAS) region Burkina Faso, Cape Verde, the Gambia, Ghana, Liberia, Niger, Nigeria, Republic of Guinea, Senegal and Togo have NMPs [14].

Medicines Laws form the foundation for regulation and they need to be comprehensive, covering all areas of pharmaceutical sector activities and a broad range of medical products, and provide adequate powers to the NMRA to control and regulate the pharmaceutical market [13]. A situational analysis of NMRAs in WHO-AFRO region shows that 40 out of 46 of the countries have legislation for medical products, though only $7(15 \%)$ of the NMRAs are legally mandated to perform all five critical regulatory functions [12]. A study conducted in the EAC Partner States revealed some commonalities and disparities of laws with varying degree of implementation and capacity [20]. In the SADC region, all 15 countries have medicines laws with varying degree of comprehensiveness, scope of regulated products, and functions [19]. For the ECOWAS region, 11 countries have medicines laws in place with similar variations, as with the SADC and EAC regions [14].

While WHO recommends that all types of medicines be regulated by NMRAs, there is wide variation across countries in Africa. Of 26 NMRAs, $65 \%$ have a mandate to control veterinary medicines; $69 \%$ had provisions for regulation of traditional or herbal medicines; $65 \%$ regulate a wide range of products including foods, pesticides, poisons, bottled water, cosmetics and/or animal food supplements; and only $15 \%$ are mandated to perform all regulatory functions [12]. The differences in legal provisions of key regulatory functions and practices have potentially delayed availability of important medicines in some markets; hence, the need for convergence towards a common medicines regulatory framework which will also facilitate benchmarking among countries in Africa.

\subsection{NMRAs Performance of Core Regulatory Functions}

Marketing authorisation (MA) Available literature on MA shows that the time it takes for the applicant to be granted MA affects availability of the product on the market. A typical lag of 4-7 years has been recorded between first regulatory submission to a well-resourced NMRA and final approval in sub-Saharan Africa [21]. Lengthy registration times is one of the reasons why companies refuse to supply medicines to certain African countries [22]. Studies also show that the growing demand to assess novel neglecteddisease products for African use have necessitated the establishment of various regulatory pathways to facilitate approval including the European Medicines Agency (EMA) Article 58; the WHO Prequalification Scheme; and the United States Food and Drug Administration (USFDA) Tentative Approval [23]. The performance of MA systems in Africa needs further research, as do licensing, import and export control systems. The available literature on the latter, conducted in Angola, indicates that licensing of pharmaceutical establishments is only granted for retail outlets, leaving the remaining supply chain unattended [24]. While the situation may not be very different in most African countries, more research is needed to determine the performance of NMRAs across the continent in this area.

Pharmacovigilance An assessment of pharmacovigilance (PV) systems in 26 sub-Saharan African countries showed that only $8(30 \%)$ countries collected reports on adverse events with only 3 programmes being sufficiently established to contribute a sizeable number of reports. Of the eight countries collecting adverse events, seven were members of the WHO Programme for International Drug Monitoring (PIDM), and in those countries where a PV system existed, it was not well integrated with other regulatory activities [12]. Membership to the WHO-PIDM is one of the criteria used to determine the performance of PV systems in a country [24, 25]. Membership requires a designated national PV centre, a spontaneous adverse drug reaction (ADR) reporting system, and demonstration of technical competence in managing individual case safety reports (ICSRs) by submitting at least 20 reports to the WHO ICSR database, VigiBase ${ }^{\mathrm{TM}}$ [26]. The number of countries that are full members of WHO-PIDM increased from five in 2000 to 35 countries in 2015 with South Africa, Morocco, Nigeria, Egypt and Kenya classified as the main ICSR reporting countries [26]. A further review of specific features of PV in Africa shows that, while the health systems are weak and lacking in basic infrastructure, personnel, equipment and facilities, they have been deploying millions of doses of medicines and vaccines to address diseases of public health importance [25], which calls for a robust PV system.

Post-Marketing Surveillance Post-marketing surveillance (PMS) activities in a country comprise an elaborate framework which includes: review of authorised products; random audits of notified variations; good manufacturing practice (GMP) inspections of local manufacturers; laboratory testing of samples either selected randomly or suspected of being substandard; monitoring of adverse drug reactions; monitoring of advertising and other promotional activities; and drug utilization studies, to mention a few [27]. The importance of PMS activities in the region is easily demonstrated: PMS of antimalarial medicines in Malawi indicated an $88.4 \%$ failure rate of samples tested, suggesting the presence of substandard products in the 
market and the need for intervention and regular monitoring to ensure delivery of quality health care [28]. In Kenya, a survey of antiretroviral medicines revealed that, while samples analysed conformed to quality standards, one-third of the products found in the market were not registered [29]. A survey of quality of antimalarial drugs circulating in Cameroon, Ethiopia, Ghana, Kenya, Nigeria and the United Republic of Tanzania indicated that $14 \%$ of collected samples were not registered by the respective NMRA and the overall failure rates of samples tested were $37,0,39,5$, 64 and $11 \%$, respectively [30]. In the case of vaccines, strong partnerships and collaboration between different stakeholders is needed to assure that vaccines are effective and safe when translated in real-world settings [31].

A low rate of post-marketing withdrawal of harmful medicinal products due to adverse drug reactions is attributed to regulatory capacity limitation by most African countries [32]. According to the WHO rapid alert system, there is increasing circulation of substandard and falsified (SSFF) medical products in the African Region and surveys show quality failure rates of up to $28 \%$ in some cases [33].

Quality Control Quality control aims to verify that products comply with specifications of MA and testing of post-marketing samples serves as a deterrent against negligent or fraudulent manufacturing and trading practice [13]. NMRAs' access to well-resourced quality control laboratories, which operate according to established standards and organisational frameworks, is key for quality surveillance of products circulating in the market [12]. The Quality Management System (QMS) ISO 17025 and the WHO Guidance on Good Laboratory Practice [34-36] are global benchmarking tools for measuring standards for QC laboratory performance. Achieving either WHO Prequalification or ISO 17,025 accreditation status ensures that a laboratory has demonstrated technical competence to produce precise and accurate data, and that it meets internationally accepted standards of quality and reliability [37].

Reports shows that 34 countries in SSA (72\%) have quality control laboratories in place, at different stages of development; 21 of these $(63 \%)$ are engaged in market surveillance [33]. There are nine WHO Prequalified Laboratories in seven African countries, namely: Adcock Ingram Limited and Research Institute for Industrial Pharmacy incorporating CENQAM (South Africa); National Pharmaceutical Control Laboratory (Algeria); Laboratory of the Mission for Essential Drugs and Supplies and National Quality Control Laboratory (Kenya); Medicines Control Authority of Zimbabwe (MCAZ) QC Laboratory (Zimbabwe); NDA-National Drug Quality Control Laboratory (Uganda); TFDA QC Laboratory (Tanzania); and the National Medicines Quality Control Laboratory (Morocco) [38]. In addition, six QC laboratories in Africa are ISO 17025 Certified [39]. These are; the
Ethiopian Food, Medicine and Health Care Administration and Control Authority (FMHACA) Laboratory Services Division (Ethiopia); Centre for Pharmaceutical Advancement and Training (CEPAT) Accra, and Food and Drugs Authority Laboratory (Ghana); Inlab Laboratoria de control de qualidade Inpharma (Cape Verde); and MCAZ (Zimbabwe) and TFDA (Tanzania).

Effective and efficient quality-control laboratories provide a useful infrastructure for PMS activities that are critical to address the challenge of the prevalence of SSFF medical products in Africa.

Clinical trials oversight In view of the high burden of diseases affecting Africa and other developing countries in the world, clinical trials are needed to develop new and effective drugs and vaccines for diseases such as HIV, TB and malaria [6, 21, 40, 41]. The increasing evidence of a shift in the location of clinical trials from industrialised to developing countries, particularly in Africa, requires an independent and strong regulatory and ethical oversight of clinical trials to ensure the safety of research subjects and scientific integrity of clinical data.

Prior to 2006, regulation of clinical trials was limited to ethics review by ethics committees (ECs) in most countries in Africa with the exception of South Africa, where there was an existing level of expertise in clinical trials oversight. Problems were compounded by a lack of legislative and regulatory frameworks for regulation of clinical trials of medicines that would keep pace with new trends in drug research and development [42, 43]. The initiation of the AVAREF by WHO in 2006 with an initial 19 membercountries, paved the way for improved performance in the approval of clinical trials for vaccines through a network of regulatory authorities and ethics committees [44, 45]. The AVAREF has, over the years, facilitated approval of important vaccines such as the conjugate meningitis $\mathrm{A}$ vaccine, which has contributed to reduction of meningitis epidemics [46, 47]. With the expansion to 23 membercountries, AVAREF has also served as a collaboration platform bringing regulators, ethics committees and sponsors together to reach consensus on key ethical and regulatory questions, particularly in addressing challenges of authorising clinical trials of Ebola candidate vaccines with limited available data in West Africa [48].

Further initiatives, which additionally promote the safe and ethical conduct of trials in Africa, include the European and Developing Countries Clinical Trials Partnership [42, 49]; the AMRH Initiative [2]; the Initiative to Strengthen Health Research Capacity in Africa [43] and the Pan-African Clinical Trials Registry (PACTR), which was established in 2012 [50]. The latter was designed to increase clinical trial registration, provide an open-access platform for free registration of clinical trials and serve the needs of Africans. PACTR, based in South Africa, works in 
collaboration with the Cochrane Infectious Diseases Group, the Cochrane HIV/AIDS Group and WHO.

\section{Opportunities for Improving Regulatory Capacity in Africa}

The AMRH Initiative, established since 2009 as part of the African Union (AU) Pharmaceutical Manufacturing Plan for Africa (PMPA), aims to improve the fragmented regulatory systems, reducing lead-time associated with meeting different country requirements and contributing to increasing availability of safe, effective, quality essential medicines for priority and neglected diseases [51]. The initiative is focused on changing from a country-focused approach to a collaborative regional approach starting by harmonizing and streamlining technical requirements for product registration and eventually expanding the scope to other product categories (e.g. NCE, vaccines, medical devices and diagnostics) and regulatory functions (e.g. clinical trials, safety surveillance).

The AMRH Initiative has worked through Regional Economic Communities (REC), with an initial pilot in the EAC region starting with harmonised guidelines for registration of medicines and GMP, QMS and Information Management Systems (IMS). As a result, NMRAs in the EAC and SADC regions have conducted joint assessment of dossiers through Collaborative Regulatory Procedures (CRP) to review applications for registration of medicinal products jointly. NMRAs in the two regions have also conducted joint GMP inspections of manufacturing sites to facilitate faster MA of products [52]. A recent pilot study conducted by Janssen Pharmaceuticals Inc., has shown that CRP work in the EAC region has led to a reduction in drug approval timelines by about 40-60\% for a number of branded medicines [53]. Initiated by Zambia, Zimbabwe, Botswana and Namibia in 2013, the Zazibona approach in the SADC region has reduced the median timeline from dossier submissions to national MA to 8 months, through CRP.

Coherence of policy and legal frameworks is another AMRH milestone which has resulted in the endorsement by the AU Heads of State and Government, in 2016, of the Model Law on Medical products Regulation, to act as a reference guide to AU Member States as they update or enact national laws [54]. Since its endorsement, 12 out of 55 countries have either reviewed or are in the process of reviewing their national laws, in line with the AU Model Law. These countries are: Ivory Coast, Burkina Faso, Seychelles, Zimbabwe, Lesotho, Namibia, Swaziland, the Gambia, United Republic of Tanzania (Zanzibar), Republic of Rwanda, Republic of Burundi and the Republic of Mozambique. The AU Model Law also facilitates countries' participation in harmonization efforts through RECs.
The launch in 2014 of 11 Regional Centres of Regulatory Excellence (RCOREs) is another key milestone which aims to address the challenge of insufficient regulatory experts in Africa [55]. RCOREs are responsible for increasing the regulatory workforce in Africa by providing sustainable training programmes in regulatory science; promoting operational research; contributing to skills enhancement by hands-on training, twinning and exchange programmes; and practical training through placement of trainees in the pharmaceutical industry. The designated RCOREs are specialised in quality assurance and quality control, PV, clinical trials oversight, medicines registration and evaluation, as well as licensing of manufacturers, inspection and surveillance, among others.

Since 2009, the United States Pharmacopeia (USP) has facilitated the establishment of a Network of Official Medicines Control Laboratories (NOMCOL) in Africa to provide a forum for sharing best practices on medicines quality issues at regional and national levels. The network offers unique inter-laboratory testing activities for participating laboratories to improve performance, as well as harmonize their drug analysis methodologies [56]. For subSaharan Africa (NOMCOL-SSA) the network comprises 16 member-countries: Botswana, Burundi, Cote d'Ivoire, Ethiopia, Ghana, Kenya, Liberia, Mali, Mozambique, Nigeria, Senegal, Sierra Leone, Tanzania, Uganda, Zambia and Zimbabwe [57]. Further North, Algeria, Egypt, Morocco, and Tunisia fall under NOMCOL_-Middle East/North Africa (NOMCOL-MENA). A total of 23 African countries (43\%) have benefited from the USP support to this network.

The opening up of AVAREF forum to all 55 African countries provides a good platform for extending support across the continent. The ongoing work to align AVAREF with AMRH will provide a comprehensive framework for ethics and clinical trial oversight for Africa to accelerate the development of new or improved medical interventions for poverty-related neglected diseases affecting the African population and provide a platform for preparedness during public health emergency. The WHO Prequalification Programme also provides a useful platform for regulatory systems strengthening and harmonization [58].

The AU Executive Council's recognition of the need to strengthen the capacity for regulation of medical products and promote harmonization serves as a foundation of establishment of the centralised African Medicines Agency (AMA). Such a body is expected to work collaboratively with NMRAs to facilitate coordination of regional harmonization efforts, provide technical guidance and ensure sustainability and reduce duplication of efforts ensuring cost-effective use of the scarce resources. In the context of AMRH and PMPA, this will provide an opportunity for sustaining the current momentum in regulatory progress that has been observed in the continent [59]. 


\section{Conclusion}

The regulatory landscape in Africa has changed remarkably over the past few years. Apart from the Sahrawi Republic, every country in Africa currently has a NMRA; although, the functionalities are variable across countries and they are at different levels of growth, maturity and expertise. At least 35 African countries (64\%) are members of PIDM with South Africa, Morocco, Nigeria, Egypt and Kenya classified as the main ICSR reporting countries. Thirty-four counties in SSA (72\%) have quality-control laboratories with different levels of development, and 21 of these (63\%) are engaged in market surveillance. However, there is a need to benchmark African NMRAs in a more transparent and objective manner, based on agreed criteria, to identify the different levels of capacities and performance. The outcome of the benchmarking process will be useful to support the ongoing harmonization efforts and facilitate capacity building among the agencies including twinning arrangements and sharing of best practices. The ongoing regulatory systems strengthening and harmonization efforts, such as AVAREF, AMRH and the planned establishment of the AMA, provide opportunities for improvement.

\section{Compliance with Ethical Standards}

Conflict of interest Margareth Ndomondo-Sigonda, Jacqueline Miot, Shan Naidoo, Alexander Dodoo and Eliangiringa Kaale have no conflicts of interest.

Funding The NEPAD Agency provided funding for this publication to be made Open Access.

Ethics Approval and Consent to Participate "Not applicable".

Consent for Publication "Not applicable".

\section{Availability of Data and Material "Not applicable".}

Open Access This article is distributed under the terms of the Creative Commons Attribution-NonCommercial 4.0 International License (http://creativecommons.org/licenses/by-nc/4.0/), which permits any noncommercial use, distribution, and reproduction in any medium, provided you give appropriate credit to the original author(s) and the source, provide a link to the Creative Commons license, and indicate if changes were made.

\section{References}

1. http://www.who.int/medicines/regulation/fact-figures-qual-med/ en/. Accessed 1 May 2017.

2. Ndomondo-Sigonda M, Ambali A. The African medicines regulatory harmonization initiative: rationale and benefits. Clin Pharmacol Ther. 2011;89(2):176-8.

3. Reggi V. Medicines regulatory harmonization: international collaboration as a key to improve public health. Med Access @ Point. Care. 2017;1(1):e2-5.
4. Nayyar GM, Attaran A, Clark JP, Culzoni MJ, Fernandez FM, Herrington JE, Kendall M, Newton PN, Breman JG. Responding to the pandemic of falsified medicines. Am J Trop Med Hyg. 2015;92(6 Suppl):113-8. doi:10.4269/ajtmh.14-0393 (Epub 2015 Apr 20).

5. Doua JY, Van Geertruyden P. Registering medicines for lowincome countries: how suitable are the stringent review procedures of the World Health Organisation, the US Food and Drug Administration and the European Medicines Agency? Trop Med Int Health. 2014;19(1):23-36. doi:10.1111/tmi.12201.

6. Lee PR, Herzstein J. International drug regulation. Annu Rev Public Health. 1986;7:217-35.

7. Goñi MC. Accelerating regulatory approvals through the World Health Organization collaborative registration procedures. Pharm Policy Law. 2016;18:109-20.

8. http://www.who.int/medicines/areas/coordination/coordination assessment/en/index1.html. Accessed 1 May 2017.

9. McBride WG. Thalidomide and congenital abnormalities. Lancet. 1961;278(7216):1358.

10. World Health Organisation. Handbook of resolutions and decisions of the World Health Assembly and the Executive Board. 1948-1972. Geneva, Switzerland: WHO; 1972. p. 139

11. WHO. 1st African Medicines Regulators Conference Final Report. WHO Regional Office for Africa, Brazzaville. 2011. 2009. http://apps.who.int/medicinedocs/documents/s17809en/ s17809en.pdf. Accessed 1 May 2017.

12. WHO. Assessment of medicines regulatory systems in sub-Saharan African countries. WHO Press, Geneva. 2010. http://apps.who.int/ medicinedocs/documents/s17577en/s17577en.pdf. Accessed 12 Dec 2016, Accessed 7 May 2017.

13. Ratanawijitrasin S, Wondemagegnehu E. Effective drug regulation-a multi country study. World Health Organisation, Geneva. 2002. http://apps.who.int/medicinedocs/pdf/s2300e/s2300e.pdf. Accessed 12 Dec 2016.

14. Kamwanja, L, Saka, J, Awotedu, A, Fute, I, Ndomondo-Sigonda, M. Situation Analysis Study on Medicines Registration Harmonization in Africa: Final Report for the Economic Community of West African States (ECOWAS). http://www.nepad.org/content/ situation-analysis-study-medicines-registration-harmonisationafrica-\%E2\%80\%93-final-report-economic. 2011. Accessed 12 Dec 2016.

15. Thumm M, Gaparay P, Goredema W, Tjipura D. Assessment of medicines regulatory systems in angola: report. Arlington: Management of Science; 2013.

16. Kamwanja L, Saka J, Awotedu A, Fute I, Chamdimba C, Ndomondo-Sigonda M. Situation analysis study on medicines registration harmonization in Africa: final report for East African Community (EAC). 2010. Lancet. 2017; 389(10082):1860. doi: 10.1016/S0140-6736(17)31272. https://scholar.google.co.za/ scholar?cluster $=6432497220577508740 \& \mathrm{hl}=\mathrm{en} \&$ as_sdt=0,5\&as_ vis=1www.nepad.org/resource/amrh-newsletter-march-2017.

17. WHO. who policy perspectives on medicines-effective medicines regulation: ensuring safety, efficacy and quality. World Health Organisation, Geneva. 2003. http://apps.who.int/iris/ bitstream/10665/68391/1/WHO_EDM_2003.2.pdf. Accessed 12 Dec 2016.

18. WHO. Guidelines for developing National Drug Policies. WHO Organisation, Geneva. 1988. http://apps.who.int/medicinedocs/ documents/s19151en/s19151en.pdf. Accessed 12 Dec 2016.

19. Kamwanja L, Saka J, Awotedu A, Fute I, Chamdimba C, Ndomondo-Sigonda M. SADC Situation analysis report. 2010. http://www.nepad.org/resource/situation-analysis-study-medicinesregistration-harmonisation-africa-final-report-southern. Accessed 12 Dec 2016.

20. Sillo HB. Comparison of medicines legislation in the East African Community. WHO Drug Inf Geneva. 2016;30(4):567-76. 
21. Ahonkhai V, Martins SF, Portet A, Lumpkin M, Hartman D. Speeding access to vaccines and medicines in low- and middleincome countries: a case for change and a framework for optimized product market authorization. PLoS One. 2016;11(11):e0166515. doi:10.1371/journal.pone.0166515 (eCollection 2016).

22. Narsai K, Williams A, Mantel-Teeuwisse AK. Impact of regulatory requirements on medicine registration in African countries-perceptions and experiences of pharmaceutical companies in South Africa. South Med Rev. 2012;5(1):31-7.

23. Moran M, Strub-Wourgaft N, Guzman J, Boulet P, Wu L, Pecoul B. Registering new drugs for low-income countries: the African challenge. PLoS Med. 2011;8:2.

24. Olsson S, Pal SN, Dodoo A. Pharmacovigilance in resourcelimited countries. Expert Rev Clin Pharmacol. 2015;8(4):449-60. doi:10.1586/17512433.2015.1053391.

25. Isah AO, Pal SN, Olsson S, Dodoo A, Bencheikh RS. Specific features of medicines safety and pharmacovigilance in Africa. Ther Adv Drug Saf. 2012;3(1):25-34. doi:10.1177/ 2042098611425695.

26. Ampadu HH, Hoekman J, de Bruin ML, Pal SN, Olsson S, Sartori D, Leufkens HG, Dodoo AN. Adverse drug reaction reporting in africa and a comparison of individual case safety report characteristics between Africa and the rest of the world: analyses of spontaneous reports in VigiBase $\left({ }^{\circledR}\right)$. Drug Saf. 2016;39(4):335-45.

27. WHO. Marketing authorization of pharmaceutical products with special reference to multisource (Generic) products: a manual for drug regulatory authorities. World Health Organisation, Geneva. 1988. http://apps.who.int/prequal/info_general/documents/WHO_ DMP_RGS_98_5_R.pdf. Accessed 12 Dec 2016.

28. Chikowe I, Osei-Safo D, Harrison JJ, Konadu DY, Addae-Mensah I, et al. Post-marketing surveillance of anti-malarial medicines used in Malawi. Malar J. 2015;14:127.

29. Njeri M, Ouma C, Kibiego P, Njuguna C, Kimeu J, Kitawi R and Nzumbu L. 2012. Post market survey of antiretroviral medicines in Kenya. NASCOP, Naiorobi. 2012. http://apps.who.int/ medicinedocs/documents/s21944en/s21944en.pdf. Accessed 13 Dec 2016.

30. WHO. Survey of the quality of selected antimalarial medicines circulating in six countries of sub-Saharan Africa. WHO Press, Geneva. 2011. http://www.who.int/medicines/publications/ WHO_QAMSA_report.pdf. Accessed 13 Dec 2016.

31. Lopalco PL, DeStefano F. The complementary roles of Phase 3 trials and post-licensure surveillance in the evaluation of new vaccines. Vaccine. 2015;33(13):1541-8. doi:10.1016/j.vaccine. 2014.10.047.

32. Onakpoya IJ, Heneghan CJ, Aronson JK. Post-marketing withdrawal of 462 medicinal products because of adverse drug reactions: a systematic review of the world literature. BMC Med. 2016;4(14):10. doi:10.1186/s12916-016-0553-2.

33. World Health Organisation. Resolution on the regional strategy on regulation of medical products in the African Region 2016-2025 (Documents AFR/RC66/13 and AFR/RC66/R2).///.

34. International Organization for Standardization. General requirements for the competence of testing and calibration laboratories. 2010. http://www.iso.org/iso/catalogue_detail?csnumber=39883. Accessed 12 Dec 2016.

35. Special Programme for Research and Training in Tropical Diseases \& WHO. Quality practices for regulated non-clinical research and development. World Health Organisation, Albany. 2009. http://site.ebrary.com/id/10411806. Accessed 12 Dec 2016.

36. WHO. WHO good practices for pharmaceutical quality control laboratories. 2010. http://apps.who.int/prequal/info_general/ documents/trs957/gpcl_trs957_annex1.pdf. Accessed 12 Dec 2016.
37. WHO. Prequalification of quality control laboratories: procedure for assessing the acceptability, in principle, of quality control laboratories for use by United Nations. 2011. http://apps.who.int/ prequal/info_general/documents/TRS961/TRS961_Annex12.pdf. Accessed 12 Dec 2016.

38. WHO List of Prequalified Quality Control Laboratories. 2016. http://apps.who.int/prequal/lists/pq_qclabslist.pdf. Accessed 12 Dec 2016.

39. The Global Fund to Fight AIDS, TB and Malaria. List of ISO 17025 quality control laboratories compliant with 'THE GLOBAL FUND' Quality Assurance Requirements. 2014. www.theglobal fund.org/documents/psm/PSM_QCLab_List_en/. Accessed 12 December 2016.

40. Dellepiane N, Akanmori BD, Gairola S, Jadhav SS, Parker C, Rodriguez C, Srivastava S. Regulatory pathways that facilitated timely registration of a new group a meningococcal conjugate vaccine for Africa's meningitis belt countries. Clin Infect Dis. 2015;15(61 Suppl 5):S428-33. doi:10.1093/cid/civ491.

41. Trouiller P, Torreele E, Olliaro P, White N, Foster S, Wirth D, Pécoul B. Drugs for neglected diseases: a failure of the market and a public health failure? Trop Med Int Health. 2001;6(11):945-51.

42. Olliaro P, Smith PG. The European and developing countries clinical trails partnership. J HIV Ther. 2004;9(3):53-6.

43. Whitworth JAG, Kokwaro G, Kinyanjui S, Snewin VA, Tanner M, Walport M, Sewankambo N. Strengthening capacity for health research in Africa. Lancet. 2008;372(9649):1590-3. doi:10.1016/S0140-6736(08)61660-8.

44. Maiga D, Akanmori BD, Chokara L. Regulatory oversight of clinical trials in Africa: progress in the past 5 years. Vaccine. 2009;27(52):7249-52.

45. Preston C, Valdez ML, Bond K. Strengthening medical product regulation in low- and middle-income countries. PLoS Med. 2012;9(10):e1001327. doi:10.1371/journal.pmed.1001327.

46. Diomandé FV, Djingarey MH, Daugla DM, Novak RT, Kristiansen PA, Collard JM, Gamougam K, Kandolo D, Mbakuliyemo N, Mayer L, Stuart J, Clark T, Tevi-Benissan C, Perea WA, Preziosi MP, Marc LaForce F, Caugant D, Messonnier N, Walker O, Greenwood B. Public health impact after the introduction of PsA-TT: the first 4 years. Clin Infect Dis. 2015;15(61 Suppl 5):S467-72. doi:10.1093/cid/civ499.

47. Kulkarni PS, Socquet M, Jadhav SS, Kapre SV, LaForce FM, Poonawalla CS. Challenges and opportunities while developing a group a meningococcal conjugate vaccine within a product development partnership: a manufacturer's perspective from the serum institute of India. Clin Infect Dis. 2015;15(61 Suppl 5):S483-8. doi:10.1093/cid/civ500.

48. Akanmori B, Bellah A, Rago L, Ward M. The African Vaccine Regulatory Forum (AVAREF): a platform of collaboration in a public health emergency. WHO Drug Inf. 2015;29(2):127-32.

49. Miiro GM, Oukem-Boyer OO, Sarr O, Rahmani M, Ntoumi F, Dheda K, Pym A, Mboup S, Kaleebu P, NoEs' programme. EDCTP regional networks of excellence: initial merits for planned clinical trials in Africa. BMC Public Health 2013;22(13):258. doi:10.1186/1471-2458-13-258.

50. The Pan African Clinical Trials Registry (PACTR). 2012. http:// www.pactr.org/. Accessed 12 Dec 2016.

51. Ndomondo-Sigonda M. The African Medicines Regulatory Harmonization Programme contribution to the African Union Pharmaceutical Manufacturing Plan for Africa. NEPAD, Johannesburg. 2012. http://www.nepad.org/resource/african-medicines-regulatoryharmonisation-amrh-programme-contribution-african-union-au. Accessed 13 December 2016.

52. WHO. WHO support for medicines regulatory harmonization in Africa: focus on East African Community. WHO Drug Inf. 2014;28(1):11-5. 
53. AMRH Newsletter, January-March 2017.

54. African Union Heads of State and Government. 2016. AU Model Law on Medical Products Regulation. www.nepad.org/download/ file/fid/5636\%20. Accessed 17 Oct 2017.

55. NEPAD. Policy Brief: understanding the role of regional centres of regulatory excellence in strengthening medicines regulation in Africa. www.nepad.org/download/file/fid/4601\%20. Accessed 17 Oct 2017.

56. Smine A, Hajjou M, Lukulay P. Establishing a network of drug quality control laboratories in USAID-Supported African Countries. United States Pharmacopeia, Maryland. 2009. http:// pdf.usaid.gov/pdf_docs/Pdaco887.pdf. Accessed 17 Oct 2017.
57. U.S. Pharmacopeia Convention. Official Medicines Control Laboratory (OMQCL) Networks. http://www.usp.org/global-healthprograms/official-medicines-control-laboratory-omcl-networks. Accessed 17 Oct 2017.

58. WHO. WHO Prequalification of Medicines Programme: facts and figures for 2011. WHO Drug Inf. 2010;25(2):101-3.

59. African Union Executive Council Decision EX.CL/872(XXVI). Twenty-sixth ordinary session, 23-27 January 2015, Addis Ababa, Ethiopia. http://www.iri.edu.ar/publicaciones_iri/anuario/ anuario_2015/Africa/29-UA-CE.pdf. Accessed 17 Oct 2017. 